\title{
APLICAÇÃO DE METODOLOGIAS ATIVAS DE APRENDIZAGEM NO ENSINO DE FONTES DE INFORMAÇÃO NO CURSO DE BIBLIOTECONOMIA
}

\author{
BRUNA LESSA
}

\begin{abstract}
RESUMO
Tem-se como objetivo, neste trabalho, relatar o uso da metodologia ativa de aprendizagem Problem Based Learning (PBL ou aprendizagem baseada em projetos/problemas) na disciplina Fontes de Informação do Curso de Biblioteconomia e Documentação, da Universidade Federal da Bahia. Isso porque, considera-seque os estudos voltados para o ensino do curso de Biblioteconomia têm se debruçado muito mais sobre os resultados das atividades aplicadas do que sobre as metodologias de ensino aplicadas nas disciplinas oferecidas em seu currículo mínimo. Para isso, apresenta-se as etapas desenvolvidas na aplicação do PBL em sala de aula. O resultado foi a criação, pelos alunos, de um catálogo on-line de fotonovelas a partir do problema apresentado. Concluiu-se que em relação aos métodos tradicionais utilizados, a aplicação do método Problem Based Learning possibilitou aos alunos vivenciar durante a graduação uma prática cotidiana do profissional bibliotecário, além de possibilitar uma abordagem interdisciplinar.
\end{abstract}

PALAVRAS-CHAVE: Metodologias de aprendizagem. Aprendizagem Baseada em Problemas. Produtos Informacionais. Fontes secundárias de informação.

\section{APPLICATION OF ACTIVE LEARNING METHODOLOGIES IN TEACHING SOURCES OF INFORMATION IN THE LIBRARY COURSE}

\begin{abstract}
Considering that the studies directed to the teaching of the Librarianship course have been much more focused on the results of the applied activities than on the teaching methodologies applied in the disciplines offered in its minimum curriculum, the objective is to present the use of the active learning methodology - Problem Based Learning (PBL) in the discipline Information Sources of the Course of Librarianship and Documentation, Federal University of Bahia. For that, the steps developed in the application of the PBL in the classroom are presented. The result was the creation, by the students, of an online catalog
\end{abstract}

* Professora Assistente B na Universidade Federal da Bahia. http://orcid.org/00000003-4485-203XInstituto de Ciência da Informação/Universidade Federal da Bahia. Departamento de Documentação e Informação - ICI/UFBA .lessbruna@gmail.com 
of photonovels from the presented problem. It was concluded that in relation to the traditional methods used, the application of the method Problem Based Learning allowed the students to experience during the graduation a daily practice of the professional librarian, besides allowing an interdisciplinary approach.

KEYWORDS: Learning methodologies. Problem Based Learning. Information Products. Secondary sources of information.

\section{INTRODUÇÃO}

O ensino da Biblioteconomia, no Brasil,no final do século XIX e início do século $X X$, é marcado pela influência francesa (humanista) e norte-americana (tecnicista).E a partir da década de 1960 começaram as discussões sobre o currículo mínimo do curso, atentando-se para sua uniformização, fortalecimento, propagação, uso de novas tecnologias e criação de cursos de pós-graduação, relacionados à área, chegando-se ao período atual, caracterizado pelas reformulações nos currículos.

Neste cenário, observa-se que os estudos voltados para o ensino do curso de Biblioteconomia têm se debruçado muito mais sobre os resultados das atividades aplicadas em sala de aula, sobretudo, no âmbito curricular.Há tendências voltadas para o trabalho do profissional da informação no mercado, a saber, seu perfil, habilidades e competências para a gestão, organização, uso e difusão da informação. Dá-se menor enfoque às metodologias de ensino aplicadas nas disciplinas oferecidas em seu currículo mínimo.

De fato, as mudanças impulsionadas pela tecnologia provocaram uma reflexão sobre as metodologias de ensino. Está em curso a vivência através das redes, a possibilidade que se tem de se intercomunicar por meio de mídias digitais, onde se aprende e ensina ao mesmo tempo, de forma síncrona e assíncrona, possibilitando ao aluno escolher como, quando e onde estudar. A partir dessas transformações, as instituições de ensino superior são condicionadas a ampliar seu papel em formar profissionais para o mercado de trabalho, além disso, elas devem, agora, formar sujeitos conscientes do seu papel social, tornando-se, com isso, participantes ativos da sociedade.

Nesta perspectiva, algumas metodologias de ensino vêm sendo aplicadas com o objetivo de preencher essa lacuna nos cursos de graduação, contribuindo para o enfoque social, político e ideológico, em detrimento ao enfoque individual. Destaca-se, aqui, 
o uso de metodologias ativas como instrumento didático na formação crítica do estudante de nível superior, tais como: Model Based Design (MBD ou projeto baseado em modelos), Flipped class room (sala de aula invertida), Problem Based Learning (PBL ou aprendizagem baseada em projetos ou problemas, Team-based learning (TBL ou aprendizagem entre pares e times), Peer Instruction (aprendizagem por pares), Writing Acrossthe Curriculum (WAC ou escrita por meio das disciplinas), Study Case (estudo de caso), Gamificação, entre outras.

Sob esta perspectiva, surge a problemática de como aplicar metodologias ativas no ensino da Biblioteconomia, sabendo-se dos benefícios que possibilitam tanto aos alunos quanto aos professores. Essas metodologias almejam colaborar para uma perspectiva formativa baseada em novos referenciais metodológicos que envolvem uma análise mais acentuada dos contextos político-sociais que relacionam termos natos da Biblioteconomia, a exemplo de usuários de informação, unidades, fontes, produtos e serviços de informação, bem como tecnologias de informação e comunicação (TIC), entre outros termos que fazem parte do cotidiano dos bibliotecários e profissionais da área.

Nesse sentido, apresentar-se-á o desenvolvimento de práticas de ensino na disciplina Fontes de Informação, do Curso de Biblioteconomia e Documentação, na Universidade Federal da Bahia (UFBA). Isso foi realizado com base na metodologia Problem Based Learning, ao longo de quatro turmas em que foram aplicadas, entre os anos de $2016 \mathrm{e} 2019$.

\section{FONTES DE INFORMAÇÃO: A IMPORTÂNCIA DA DISCIPLINA NO CURSO DE BIBLIOTECONOMIA E DOCUMENTAÇÃO}

O uso das fontes de informação, no contexto da pesquisa científica, possui grande relevância, em especial, no entendimento sobre os conceitos de fontes primárias, secundárias e terciárias. Para Campello, Cendón e Kremer (2000), as fontes primárias possuem informações novas, que ainda não foram publicadas ou estão no início do processo da pesquisa e, por isso, em alguns casos são mais difíceis de localizar, a exemplo de relatórios técnicos, patentes, normas técnicas, etc. Já as fontes secundárias reúnem informações de forma organizada, direcionando o leitor para as fontes primárias e facilitando o seu uso, como é o caso dos dicionários, livros e blogs. As fontes terciárias indicam a localização, ou ainda, onde buscar fontes primárias e secundárias, 
representadas em forma de diretórios, guias bibliográficos, serviços de indexação e resumos.

Esta compreensão coloca em evidência o papel do bibliotecário enquanto mediador no processo de busca e recuperação da informação, ao auxiliar usuários que necessitam do uso diário de informação especializada para realizar suas pesquisas. A partir disto, faz-se necessário, durante a graduação no curso de Biblioteconomia, aprender sobre a tipologia das fontes de informação para que se possa direcionar e orientar os usuários no acesso, uso e recuperação da informação, de forma precisa, competente e útil para o desenvolvimento de seus estudos.

No âmbito da Gestão da Informação, o conhecimento sobre fontes de informação também se faz presente para observar as funções de uma Unidade de Informação. Entre estas funções, destaca-se a promoção do acesso à informação, possibilitando, de forma estratégica que o usuário adquira competência em informação ao manusear um item informacional, reconhecendo a credibilidade da fonte, sabendo utilizá-la assertivamente.

No ambiente virtual, em que a possibilidade de ocorrer a alteração da validação de documentos é maior que no ambiente físico, as fontes digitais e virtuais demandam do usuário habilidades, caso contrário, serão utilizadas fontes sem credibilidade em suas pesquisas. Do mesmo modo, subtende-se que o bibliotecário possua competências em informação e comunicação para localizar a informação contida em fontes informacionais em qualquer meio, impresso ou virtual, além de produzi-las de acordo com a necessidade dos usuários.

Sobre esta relação entre competência em informação e o ensino de Fontes de Informação, Correa, Lucas e Muller (2018), a partir de uma análise documental, identificaram que a aplicação de determinado modelo de competência em informação possibilita ao estudante de Biblioteconomia o desenvolvimento de atitudes na atuação como mediador no processo de busca, acesso e apropriação da informação. Isso ocorre para que, quando se tornar um bibliotecário, possa solucionar problemas e colaborar para a construção de um espaço de conhecimento junto à comunidade que esteja inserido. Para Almeida Júnior (2015, p. 25) a mediação da informação é:

Toda ação de interferência realizada em um processo, por um profissional da informação e na ambiência de equipamentos informacionais, direta ou indireta; consciente ou inconsciente; 
singular ou plural; individual ou coletiva; visando a apropriação de informação que satisfaça, parcialmente e de maneira momentânea, uma necessidade informacional, gerando conflitos e novas necessidades informacionais.

No conceito reformulado por Almeida Júnior (2015), a ação de mediação realizada pelo profissional da informação acontece em ambientes múltiplos e híbridos a partir da necessidade informacional do usuário. Além disso, existem ações indiretas nesse processo que incluem a seleção e análise de fontes de informação para sua posterior disseminação e uso, tornando com isso, a mediação da informação um processo amplo e complexo. Sob esta ótica, percebe-se que o papel do mediador é de construir o caminho para que o outro possa transformar a informação em conhecimento, ou seja, não é apenas o de promover uma interação entre os elementos envolvidos (informação e usuário) ou simplesmente possibilitar a circulação de informação.

Tais atitudes mediadoras também incluem competências no uso de linguagens documentárias somadas às estratégias de busca de informação em sistemas automatizados. Associado a esta habilidade necessária ao futuro bibliotecário, tem-se o tratamento e organização da informação, atividade que está diretamente associada a apropriação da informação pelo usuário, uma vez que a informação organizada se torna mais acessível e pronta para uso, sendo, portanto, imprescindível conhecer os tipos de fontes de informação que se pretende disseminar.

Nesse sentido, o ensino da disciplina Fontes de informação possui grande importância para as atividades que serão desenvolvidas pelo profissional bibliotecário, pois trata-se de uma disciplina voltada para a análise e uso de informações disponibilizadas em diversos formatos e que, muitas vezes possuem viés estratégico para tomada de decisões, seja numa pesquisa científica, ou ainda, em diferentes tipos de organizações.

A criação e inovação em produtos e serviços de informação é consequência do conhecimento sobre as fontes de informação adequadas. Assim, a partir do ensino sobre Fontes de Informação é possível, ao aluno do Curso de Biblioteconomia, aprender a elaborar instrumentos bibliográficos para o auxílio na disseminação e acesso a publicações. Em geral, tais instrumentos auxiliam o usuário na recuperação da informação, classificados por Cunha (2001, XXI) como:

[...] documentos secundários: contêm informações sobre documentos primários e são arranjados segundo um plano definitivo; são, 
na verdade, os organizadores dos documentos primários e guiam o leitor para eles; documentos terciários: têm como função principal ajudar o leitor na pesquisa de fontes primárias e secundárias, sendo que, na maioria, não trazem nenhum conhecimento ou assunto como um todo, isto é, são sinalizadores de localização ou indicadores sobre os documentos primários ou secundários, além de informação factual; este livro é um exemplo de documento terciário.

Nesta perspectiva, a elaboração desses instrumentos caracteriza mais um dos produtos e serviços desenvolvidos pelo profissional bibliotecário para facilitar a busca, acesso e uso da informação.

\section{O USO DE METODOLOGIAS ATIVAS NA DISCIPLINA FONTES DE INFORMAÇÃO, DO CURSO DE BIBLIOTECONOMIA E DOCUMENTAÇÃO}

O ensino da Biblioteconomia, no Brasil, surgiu a partir do Decreto 8.835 , de 11 de julho de 1911, que estabeleceu a criação do primeiro Curso de Biblioteconomia na Biblioteca Nacional, Rio de Janeiro, iniciando, efetivamente, em abril de 1915. No ano de 1929, em São Paulo, surgia o "Curso Elementar de Biblioteconomia" no Mackenzie College, orientado pela bibliotecária americana Dorothy Muriel Gedds Gropp. No entanto, foi a partir da década de 1930, que a profissão de bibliotecário ganha destaque, principalmente após a aprovação da Lei 2.839, promulgada em 5 de janeiro de 1937, Lei das Bibliotecas. Na referida Lei, fora estabelecido que só seriam admitidos como bibliotecários aqueles que apresentassem diploma de Curso Superior e de Biblioteconomia. (CASTRO, 2000).

Com o desenvolvimento de novas reformas administrativas voltadas para tal ofício, bem como o aumento de recursos orçamentários para 0 ensino da Biblioteconomia, tornou-se necessária à criação de novas Escolas em outras capitais brasileiras. Assim, no ano de 1942, na Bahia, surge a terceira Escola de Biblioteconomia do Brasil, dirigida por Bernadette Sinai Neves. Desde então, a Biblioteconomia brasileira vem evoluindo de forma significativa, nas ações e práticas voltadas para a formação de profissionais cada vez mais capacitados a organizar e disseminar a informação, levando em consideração as transformações sociais e culturais na sociedade.

A Bahia, estado onde surgem as primeiras bibliotecas do Brasil, possui grande relevância no cenário nacional em relação 
à importância social e educativa, no que se refere ao tema Bibliotecas e Bibliotecários. O Curso de Biblioteconomia e Documentação, que integra, hoje, os cursos de graduação disponibilizados pelo Instituto de Ciência da Informação (ICl), da Universidade Federal da Bahia (UFBA), comemora 77 anos da sua existência, no ano de 2019.

Na Bahia, o ensino sobre Fontes de informação surgiu em 1978, não como uma disciplina do currículo mínimo, mas como um curso de extensão intitulado "As fontes de informação na Biblioteca Pública", ministrado pela Profa. Maria de Lourdes do Carmo Conceição, no município de Cachoeira/Ba. Isso correu através da parceria entre a Escola de Biblioteconomia e Comunicação (EBC) e o Programa de Desenvolvimento de Cachoeira (PRODESCA). Na década de 1980, o currículo foi reformulado, e o então Departamento Documentação e Informação, em 1987, passou a contar com 17 disciplinas profissionalizantes, incluindo "Fontes Bibliográficas I: biomédicas", "Fontes Bibliográficas II: tecnologia" e "Fontes Bibliográficas III: ciências sociais" como disciplinas optativas.

A partir de 1997, o currículo mínimo do curso passou a incluir Fontes de Informação, como disciplina obrigatória, mantendo-a como obrigatória até hoje.Nesse contexto, ao refletir sobre os desdobramentos nas atividades do profissional bibliotecário a partir do aprendizado na disciplina Fontes de Informação, decidiu-se adotar outras metodologias ativas de ensino-aprendizagem na referida disciplina. Esta foi ministrada com o objetivo de proporcionar aos alunos o desenvolvimento da criatividade e da curiosidade, de modo a favorecer o protagonismo e a autonomia e, estimulando a tomada de decisões, de forma individual e coletiva, a partir do contexto estudantil e da sociedade como um todo.

Para isso, num primeiro momento, construiu-se um mapa (Figura 1), baseado no ementário da disciplina, a fim de categorizar e organizar as estruturas lógicas de cada conteúdo e identificar suas conexões, para que não houvesse nenhum choque com a mudança na prática pedagógica, preservando cada etapa do conteúdo programático. Este cuidado partiu das reflexões trazidas por Piaget (2002), ao perceber que o conhecimento se dava por descobertas, como resultado de uma interação, da qual o sujeito é sempre um elemento ativo, que procura diligentemente compreender o mundo que o cerca, e que busca resolver as interrogações que ele provoca. Para Piaget (2002), todo ser humano é capaz de construir conhecimento, denominando-o de "sujeito epistêmico". Nesse sentido, a motivação para a geração do conhecimento nasce a partir 
da interação do sujeito com o ambiente, permitindo a organização dos significados em estruturas cognitivas.

Figura 1 - Mapa do componente curricular Fontes de Informação

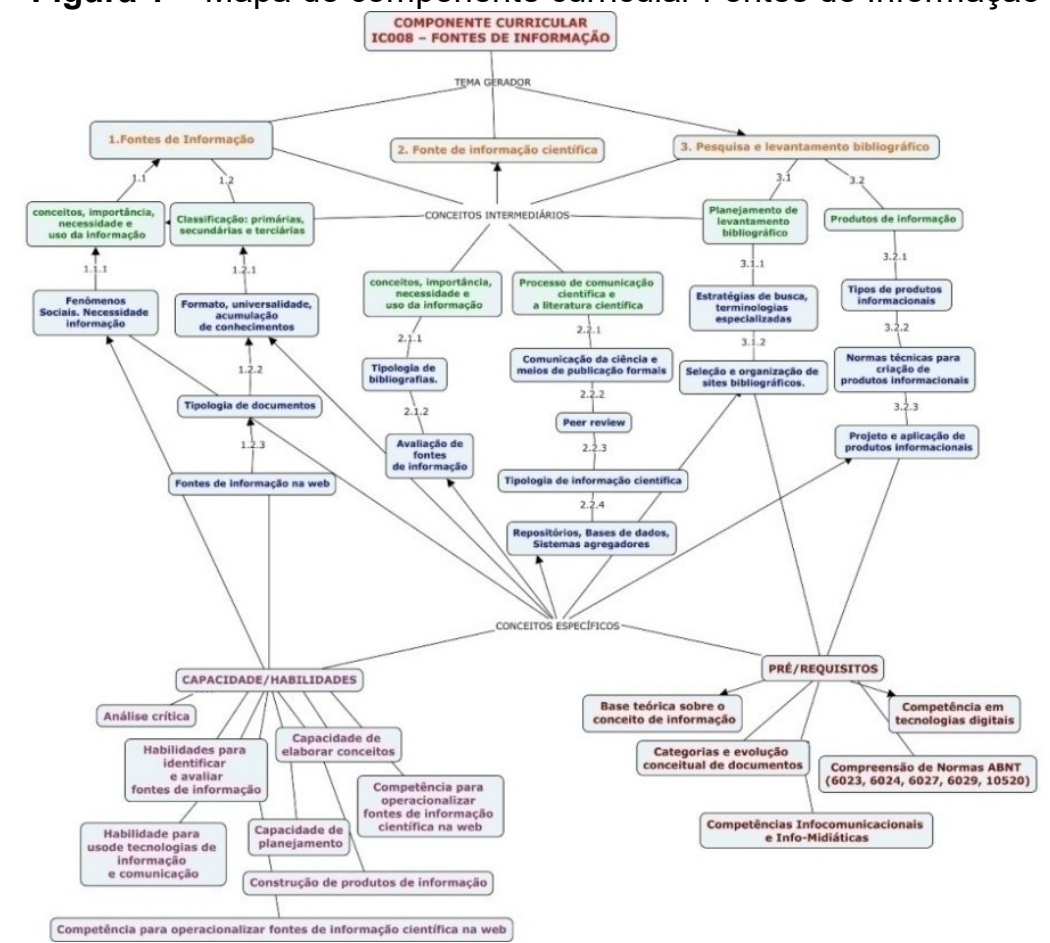

FONTE: Elaboração da autora.

Seguindo a premissa anterior, baseada na interação, fez-se uma associação com a dicotomia entre conhecimento tácito e explícito, proposta por Nonaka e Takeuchi (1997). Os autores apontam a socialização como um dos elementos existentes no início do processo de construção do conhecimento, ou seja, o diálogo, observação, experiência, com outros indivíduos possibilitam o compartilhamento do conhecimento tácito. Para Piaget (2002) há, nesse processo, a assimilação e o conflito cognitivo, que ocorrem quando a interação com o objeto gera um conflito - lançando um desafio para que o indivíduo busque o conhecimento. (RICHMOND, 1981).

Desse modo, o sujeito é o protagonista na aquisição do conhecimento. Isto acontece devido a sua interação com o meio e a ações mediadoras que o ambiente provoca, pois aprender 
é um processo ativo no qual o significado é desenvolvido com base em experiências. Neste ponto, entra o papel do professor na perspectiva de Piaget (2002) - o papel mediador - que orienta e cria conflitos para possibilitar possíveis erros e, com isso, gerar inovações e construções do novo. A compreensão da cognição, em Piaget (2002), pode ser observada na relação entre cognição e aprendizagem para a construção da inteligência, por meio de operações mentais, na interação sujeito-objeto, numa concepção de que o desenvolvimento cognitivo engloba a aprendizagem. A conexão com outras áreas do saber é vista como algo positivo, pois $O$ autor considera a interdisciplinaridade como um enriquecimento recíproco. (PIAGET, 1972).

É neste cenário que se inserem as metodologias ativas de aprendizagem. Nelas "[...] o aprendizado se dá a partir de problemas e situações reais; os mesmos que os alunos vivenciarão depois na vida profissional, de forma antecipada, durante o curso." (MORÁN, 2015, p.19). Diante desses pressupostos, dentre as metodologias ativas de aprendizagem, optou-se pela aplicação da Metodologia da Problematização, ou ainda do PBL - Problem Based Learning (aprendizagem baseada em problemas), que para Ribeiro (2008, p. 24)

[...] é uma metodologia de ensino e aprendizagem que utiliza problemas coerentes para com a futura atuação dos alunos como profissionais e cidadãos para iniciar, enfocar e motivar a aprendizagem dos conhecimentos conceituais, procedimentais e atitudinais objetivados [...] fundamenta-se em princípios educacionais e em resultados da pesquisa em ciência cognitiva, os quais mostram que a aprendizagem não é um processo de recepção passiva e acumulação de informações, mas de construção de conhecimentos.

Considerando estes aspectos conceituais sobre o PBL, é interessante perceber que, tanto o aluno quanto o docente, atores principais neste processo pedagógico, estabelecem relações mais próximas. Essas relações ocorrem quando o aluno desenvolve a responsabilidade e curiosidade, a partir da motivação em solucionar problemas e, o professor passa a ser mais que um transmissor de conteúdos. Ele é encorajado a promover mudanças na estrutura instrucional e avaliativa, valorizando o conhecimento dos alunos, ensinando e apreendendo ao mesmo tempo.

A responsabilidade, neste método educacional, talvez possa ser considerada um dos fatores mais positivos de sua aplicação, já que os próprios alunos criam um ambiente de aprendizado, na medida em que novos problemas vão sendo suscitados dentro de 
uma determinada problemática, ensinando-os, com isso, a serem eternos aprendizes. Pois, acredita-se que, embora haja uma reformulação curricular sempre que novas tendências surgem em resposta às exigências, evolução e demandas da sociedade, muito do conhecimento aprendido na graduação se tornará obsoleto em sua vida profissional.

De acordo com Souza e Dourado (2015), para a aplicação do PBL são consideradas características que contribuem para o sucesso do método, descritas a seguir.

A primeira delas é o aluno como protagonista da aprendizagem. A exposição de problemas estimula a participação individual e em grupo, fomentando a criticidade e reflexão nas discussões, possibilitando a construção de soluções transdisciplinares a partir das experiências de vida de cada aluno, dos conceitos apresentados em sala de aula e conexões com o cotidiano, oportunizando a criação de novos conhecimentos mediados pela interação social. Tem-se ainda, o trabalho em grupo.

No PBL esta ação tem por objetivo a valorização da convivência. $O$ aluno assume o perfil de investigador, participando das discussões, envolvendo outros em suas reflexões, corroborando para uma formação pessoal e social baseada numa aprendizagem colaborativa, a qual dá subsídios para a reconstrução do conhecimento e atitudes solidárias, que surge com a correção mútua, a espera pelo tempo de aprendizado do outro e o respeito pelas ideias divergentes. Por último, uma das características do PBL é o professor como tutor. Seu papel possui destaque para que o processo de aprendizagem seja bem-sucedido. É necessário que haja uma interação entre o professor, o aluno e o conteúdo aplicado e discutido.

A importância do professor tutor pode ser resumida nas seguintes atividades:

assumir a responsabilidade pela criação e apresentação do cenário problemático; colaborar com o processo de aprendizagem; ajudar na aprendizagem dos conhecimentos conceituais da disciplina; acompanhar o processo de investigação e resolução dos problemas; potencializar o desenvolvimento das competências de análise e síntese da informação; ser corresponsável na organização do espaço de encontro e relações no grupo; favorecer a criatividade que proporciona a independência dos alunos ao abordar os processos cognitivos. (SOUZA; DOURADO, 2015, p.190).

O professor cria situações de aprendizagem, contribuindo com possíveis conexões entre a proposta curricular de ensino e as 
experiências de cada aluno, complementando todo o conhecimento adquirido no conteúdo desenvolvido nas aulas. Assim, tem a função de motivar a autonomia dos alunos na construção do conhecimento. Na próxima seção, apresentaremos como se deu a aplicação do PBL na disciplina Fontes de Informação, escolhendo-se a turma de 2018.

\section{APLICAÇÃO DO PBL NA DISCIPLINA FONTES DE INFORMAÇÃ̃O}

Para aplicação do método PBL na disciplina Fontes de Informação foi, inicialmente, escolhido um tema a partir da estrutura curricular da disciplina. Assim, antes da implantação da metodologia, apresentaram-se aulas expositivas, visitas técnicas e textos que possibilitassem uma fundamentação teórica e experiências vivenciadas nas visitas, potencializando discussões sobre a temática.

Após esta etapa, foi realizada a organização do grupo de acordo com as funções de cada participante (Quadro 1):

\begin{tabular}{|c|c|c|}
\hline FUNÇÃO & CATEGORIA & ATRIRUC ÃO \\
\hline Tutor & Professor & Orientar os alunos nas discussões. \\
\hline Coordenador & Aluno & $\begin{array}{c}\text { Desenvolver a liderança do grupo, } \\
\text { estimulando os outros alunos a } \\
\text { participarem da discussão, administrando } \\
\text { o tempo de cada um e assegurando o } \\
\text { cumprimento das atividades. }\end{array}$ \\
\hline Secretário & Aluno & $\begin{array}{l}\text { Registrar as ideias em relatórios, de } \\
\text { maneira a organizar as sugestões para } \\
\text { resolução do problema, facilitando com } \\
\text { isso o direcionamento das discussões. }\end{array}$ \\
\hline $\begin{array}{l}\text { Demais } \\
\text { Darticipantes }\end{array}$ & Alunos & Discutir a problemática. \\
\hline
\end{tabular}

FONTE: Elaboração da autora.

A organização do grupo de ensino pelo método PBL prevê que os próprios alunos indiquem quem assumirá as funções de coordenador e secretário em cada sessão de discussão, ou seja, há um rodízio entre os participantes de modo que possibilite a todos conhecer e desempenhar cada função.

Seguiu-se a fase da apresentação da temática "Necessidade Informacional" e do projeto em formato de problema,com base nos processos: 
1. apresentação do problema aos alunos. O problema em questão partiu de uma situação fictícia, elaborada por esta docente, recorrente em unidades de informação relacionado a necessidades informacionais;

2. discussão sobre o problema;

3. debate sobre possíveis soluções para o problema. Nesta fase, a análise e o registro das ideias foram importantes para posteriormente verificar sua aplicabilidade;

4. organização das ideias coletadas para estruturar a solução final;

5. discussão sobre possíveis lacunas de conhecimento e/ou elementos e habilidades necessárias para compreensão do problema e apresentação de uma possível solução. Nesta fase, os alunos foram levados a sistematizar o conteúdo aprendido em sala sobre fontes de informação em grupo e individualmente;

6. após sistematização coletiva e individual, os alunos sentiram-se preparados para definir estratégias para resolução do problema, que foram a busca de novas leituras relacionadas ao tema, visitas técnicas a possíveis unidades de informação que poderiam contribuir para a solução da problemática, entrevistas e outros recursos;

7. os alunos se reuniram para debater o cenário do problema e definir como aplicar e apresentar a solução.

Importante salientar que, nesta etapa, todos os alunos foram orientados a desenvolver uma prática coletiva para a resolução do problema. Nesse momento, a figura do professor-tutor é de suma importância, uma vez que fomenta a socialização e o trabalho em grupo, estimulando os alunos a pensar e refletir sobre o tema, mediando os conflitos e incentivando o lugar da escuta, possibilitando, com isso, que todos os participantes possam contribuir e se sentir protagonista na resolução da problemática em foco.

Com o término da etapa e contextualização do tema, os alunos chegaram à solução do problema apresentado:

[...] um estudante de doutorado em Comunicação Social, decidiu estudar sobre o assunto, no que tange à memória das principais revistas de fotonovelas no Brasil e que possuem exemplares em Salvador. Discutindo sobre a questão com alguns colegas, foi sugerido por onde começar: um colega recomendou que o estudante fizesse um levantamento em uma base de dados da Universidade, 
um outro disse que era melhor ir atrás de colecionadores de fotonovelas, um terceiro questionou se haveria em Salvador alguma Unidade de Informação que mantivesse a guarda e preservação de alguns exemplares. No entanto, seu orientador aconselhou que o estudante deveria analisar todas as considerações feitas pelos colegas e listar, de forma ordenada, as referências ou inscrições que registram as peças da coleção, de modo que posteriormente, tanto o estudante, quanto os leitores de sua tese possam encontrar/localizar as fotonovelas pela descrição temática, e/ou pela descrição física. Surgiram mais dúvidas na cabeça do estudante: qual(is) fontes de informação devo procurar? Onde localizá-las? Qual o produto final deste levantamento? Como iniciar a pesquisa? Partir de uma publicação que resume, analisa e discute informações já publicadas?

As questões suscitadas no problema possibilitaram a discussão de qual seria a solução mais adequada, de acordo com o perfil do "estudante de doutorado", citado no texto, a partir de sua necessidade informacional. Para isso, os alunos chegaram à seguinte estratégia:

1. escolha do tipo de fonte de informação adequada a necessidade informacional do usuário;

2. localização de onde se encontram tais fontes;

3. definição da estratégia de busca e levantamento bibliográfico;

4. definição do tipo e qual fonte de informação atenderia a necessidade do usuário;

5. planejamento da elaboração de um produto informacional especializado para o usuário em questão.

Para levantamento e coleta das fontes de informação, foram realizadas visitas técnicas em Unidades de informação, tais como: o Arquivo Histórico Municipal da Fundação Gregório de Mattos, o Arquivo Público do Estado da Bahia, o Instituto de Radiodifusão Educativa da Bahia, o Instituto Histórico e Geográfico da Bahia, a Escola de Belas Artes, a Biblioteca Macêdo Costa da UFBA, o Gabinete Português de Leitura, a Biblioteca Pública do Estado da Bahia (BPEB), onde foi possível localizar a coleção da Revista Rainha no período de 1960 a 1970. No problema apresentado, o período indicado para a pesquisa do "estudante de doutorado" foi o das décadas de 1950 a 1970, quando, no Brasil, as fotonovelas tiveram um mercado cativo por mais de 25 anos, com milhões de leitores de histórias publicadas em revistas com grande circulação nacional.

O produto final, como resultado para solução do problema proposto, foi o Blog do acervo de fotonovelas (http://fotonovelasinfor. blogspot.com/), produzido pelos próprios alunos (Figura 2). 
Figura 2 - Blog do Acervo Fotonovelas da BPEB
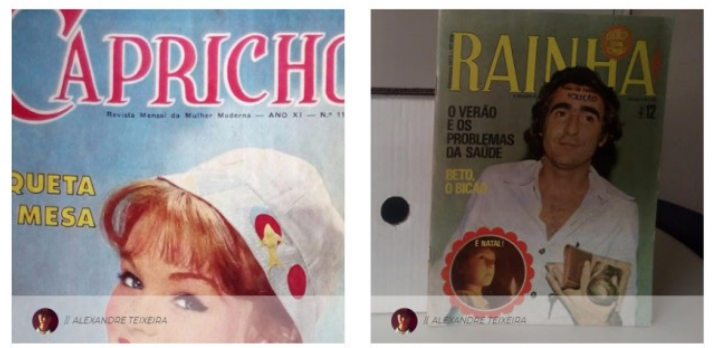

MEMÓRIA DAS FOTONOVELAS NO BRASIL E...

FOTONOVELAS: ONDE COMPRÁ-LASI

de ser possivel consultar o acervo das biblilotecas

FONTE: Consultoria (ano, 2019).

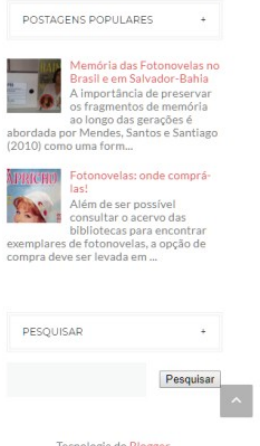

O acervo utilizado para criação do blog foi o do Setor de Periódicos BPEB, o qual possibilitou reunir alguns exemplares de fotonovelas nacionais, localizados em território soteropolitano, resgatando a memória da antiga mídia brasileira, já que não possui nenhum recurso informacional que disponibilize esse acervo em ambiente virtual.

\subsection{O protagonismo dos estudantes do curso de Biblioteconomia na criação de fontes de informação}

Com o desenvolvimento teórico ministrado na disciplina, viu-se a necessidade de expandir a prática para além da sala de aula. Assim, o uso de fontes de informação que retratam aspectos culturais e morais de décadas passadas, a exemplo das fotonovelas, contribuiu para a reflexão de outros temas sociais, sobretudo os postos pré-determinados para cada gênero (principalmente das mulheres que eram o público-alvo destas publicações).

Desse modo, os alunos tiveram que mergulhar no teor histórico, cultural e social do tema para desenvolver o produto informacional, observando-se, com isso, a necessidade da interdisciplinaridade na atuação do profissional bibliotecário. O enfoque deu-se, sobretudo, na questão do empreendedorismo e do intra-empreendedorismos, já que os estudantes foram incentivados a fazer um levantamento bibliográfico personalizado e, 
consequentemente, a elaboração de um produto específico voltado para a necessidade de um usuário, indicando outro viés da profissão, que é a consulta informatológica.

Após a conclusão da atividade, o Blog do acervo de fotonovelas da BPEB foi divulgado no Instituto de Ciência da Informação e nos canais de comunicação da Fundação Pedro Calmon (FPC), autarquia que administra a Biblioteca Pública do Estado da Bahia. Além disso, a experiência de monitoria de uma das alunas do Curso na disciplina foi apresentado no Congresso de Pesquisa, Ensino e Extensão da UFBA, evento que tem como objetivo promover" [...] um espaço de interlocução entre os mais diversos saberes produzidos nos programas de assistência estudantil e de fomento à pesquisa, extensão e ensino na UFBA [...]". (CONGRESSO...2018, on-line).

Importante considerar, nesse processo metodológico de aprendizagem, no âmbito da graduação, que a formação teórica e prática, como profissional do trabalho na área, não sejam desassociadas. Nesse sentido, o maior desafio na construção de bibliotecários é constituir práticas de ensino que se adéquem à nova realidade mercadológica, frente aos avanços na criação, uso e acesso da informação, promovendo dinâmicas que estimulem e orientem novos aprendizados.

Alguns relatos sobre a experiência dos alunos com o método PBL, aplicado, foram extraídos dos relatórios individuais da atividade e acentuam a importância da manutenção de metodologias ativas no ensino da graduação:

Foi, para mim, uma experiência incrível e proveitosa, de muito aprendizado. (Estudante A)

"Ao meu ver, minha participação foi excelente, pois estive presente em todos os encontros, opinei sobre os temas e tentei aprender coisas novas para agregar valor à equipe. A experiência do projeto foi muito gratificante, pois foi possível aprender na prática e interagir com a comunidade externa." (Estudante B)

"Este trabalho foi de suma importância, pois foi desempenhado por toda equipe com total dedicação e comprometimento, além de todo aprendizado sobre as fontes de informação. O que mais foi gratificante nesse projeto, foi à relação direta com os usuários da informação, e o papel do bibliotecário perante as necessidades emergentes dos mais jovens em acessar e consumir uma informação de qualidade." (Estudante $\mathrm{C}$ ) 
"[...] todos se envolveram e fizeram o trabalho no geral, a experiência foi maravilhosa de grande aprendizado, conhecimento e crescimento não só acadêmico, mas como pessoa também," (Estudante D)

Por fim, a experiência na aplicação do método PBL, como docente, permitiu refletir sobre o papel do professor na interação entre aprendizado e desenvolvimento dos alunos. A atenção que se deve ter com cada estudante para compreender sua forma de aprender exige dedicação e esforço, todavia, o resultado deste envolvimento retrata o comprometimento dos futuros profissionais em suas ações no mercado de trabalho. Assim, despertar possibilidades de aprendizado, incentivar futuras pesquisas, ou ainda, favorecer a identificação de novas problemáticas e possíveis soluções, representam o verdadeiro papel do professor, enquanto agente mediador em uma sala de aula.

\section{CONSIDERAÇÕES FINAIS}

Em relação aos métodos tradicionais utilizados, a aplicação do método PBL, na disciplina de Fontes de Informação, possibilitou aos alunos vivenciar uma prática do cotidiano do profissional bibliotecário em sala de aula, e fora dela, quando tiveram que ir a busca das fontes necessárias para o usuário trazido no problema. Ademais, possibilitou uma abordagem interdisciplinar, ao utilizar o conhecimento adquirido pelos alunos em outras disciplinas, a exemplo das disciplinas de Editoração e Tecnologia da Informação. Além disso, a autonomia dos alunos em definir suas estratégias de aprendizagem possibilitou que assumissem o papel de protagonistas nesse processo, utilizando ativar conhecimentos adquiridos em outras disciplinas no curso e/ou ao longo de sua vida, seja acadêmica ou não, transferindo seu aprendizado de uma situação para outra.

O fato de trazer um problema a ser resolvido pelos alunos como recurso de aprendizagem permitiu explorar, também, diversos assuntos. Desse modo, conectando-os aos temas abordados na disciplina, estimulando e motivando a discussão e o diálogo entre os participantes.

Importante destacar que, ao final da disciplina, os alunos estavam se relacionando mais uns com os outros e contribuindo para a aprendizagem ao longo da vida. Isso porque,enquanto profissionais, as habilidades de discussão, de escuta, de trabalho em equipe e resolução de problemas serão imprescindíveis para o sucesso em suas carreiras. 
Desse modo, a experiência no desenvolvimento do método PBL alcançou seu objetivo principal, que foi o de favorecer o desenvolvimento de habilidades em raciocínio científico, autoestudo e autoavaliação. Vê-se, com isso, que novas propostas metodológicas devem ser utilizadas nos cursos de Biblioteconomia, de maneira que os futuros bibliotecários e bibliotecárias possam viver experiências práticas ainda na graduação, contribuindo, assim, para a formação de profissionais cada vez mais competentes e dinâmicos em suas atividades.

\section{REFERÊNCIAS}

ALMEIDAJÚNIOR, O. F. de. Mediação da Informação: um conceito atualizado. In: BORTOLIN, S.; SANTOS NETO, J. A. dos; SILVA, R. J. da (Org.). Mediação Oral da Informação e da Leitura. Londrina: Abecin, 2015. p. 9-32.

ARAUJO, Nelma Camêlo; FACHIN, Juliana. Evolução das fontes de informação. Biblos: Revista do Instituto de Ciências Humanas e da Informação, v. 29, n. 1, 2015.

BUFREM, Leilah Santiago (Coord.). Catálogo coletivo de dicionários da língua portuguesa em bibliotecas de Curitiba. Curitiba: Departamento de Biblioteconomia da UFPR, 1993.

CAMPELLO, Bernadete Santos; CENDÓN, Beatriz Valadares; KREMER, Jeannette Marguerite. Fontes de informação para pesquisadores e profissionais. Belo Horizonte, MG: Ed. da UFMG, 2000.

CAMPELLO, Bernadete Santos; CALDEIRA, Paulo da Terra (Org.). Introdução às fontes de informação. 2. ed. Belo Horizonte: Autêntica Editora, 2008.

CASTRO, César. História da biblioteconomia brasileira. Brasília: Thesaurus, 2000.

CORREA, Elisa Cristina Delfini; LUCAS, Elaine Rosangela de Oliveira; MULLER, Viviane Formighieri. Conexão entre competência em informação e as disciplinas Fontes de informação e Serviço de Referência: um mapa conceitual. RDBCI: Rev. Digit. Bibliotecon. Cienc. Inf., Campinas, v. 16, n. 2, p. 501-521, mai./ago. 2018. Disponível em: <https://periodicos.sbu.unicamp.br/ ojs/index.php/rdbci/article/view/8649760/pdf. Acesso em: 11 jun. 2018.

CONGRESSO PESQUISA, ENSINO E EXTENSÃO DA UFBA,2018, Salvador. E agora, Brasil? A universidade e os desafios desses novos tempos. Disponível em: http://www.congresso2018.ufba.br/. Acesso em: 10 out. 2019. 
CONSULTORIA

INFORMATOLÓGICA.

Disponível

em:

http://fotonovelasinfor.blogspot.com/. Acesso em: 12 jan. 2019.

CUNHA, Murilo Bastos da. Para saber mais: fontes de informação em ciências e tecnologia. Brasília:Briquet de Lemos / Livros, 2001.

MORÁN, José. Mudando a educação com metodologias ativas. In: SOUZA, Carlos Alberto de; MORALES, Ofelia Elisa Torres (Orgs.). Convergências Midiáticas, Educação e Cidadania: aproximações jovens. PG: Foca FotoPROEX/UEPG, 2015.

NONAKA, I.; TAKEUCHI, H. Criação de conhecimento na empresa: como empresas japonesas geram a dinâmica da inovação. Rio de Janeiro: Campus, 1997

PIAGET, Jean. Méthodologie des Relations Interdisciplinaires. Archives de Philosophie, 34, 1972. p. 539-549.

PIAGET, Jean.Epistemologia genética. Tradução Álvaro Cabral; revisão da tradução Wilson Roberto Vaccari. 2. ed. São Paulo: Martins Fontes, 2002.

PEREIRA, Edmeire Cristina; BUFREM, Leilah Santiago.Fontes de informação especializada: uma prática de ensino-aprendizagem com pesquisa na Universidade Federal do Paraná. Perspect. cienc. inf., Belo Horizonte, v. 7, n. 2, p. 197-206, jul./dez. 2002.

PRYSTHON, Cecília; SILVEIRA;Murilo A. A. da; SILVA, Lígia S. da. O mundo pernambucano através de fontes deinformação: 1965-2003. Inf., Londrina, v. 13, n. 2, p. 96-107, jul./dez. 2008.

REIS; Margarida Maria de Oliveira; BLATTMANN, Úrsula; REIS, Valéria. Acesso e uso de fontes de informação on-line no ambiente de ensino e pesquisa. In: Seminário Nacional de Bibliotecas Universitárias, 13., 2004, Natal. Anais... Natal, RN: BCZM, 2004.

RIBEIRO, Luis Roberto de Camargo. Aprendizagem baseada em problemas (PBL) na educação em engenharia. Revista de Ensino de Engenharia, v. 27, n. 2, p. 23-32, 2008. Disponível em:https://www.researchgate.net/ publication/268183847_APRENDIZAGEM_BASEADA_EM_PROBLEMAS_P BL_NA_EDUCACAO_EM_ENGENHARIA. Acesso em: 12 jun. 2018.

RICHMOND, P. G. Piaget: teoria e prática. 3. ed. São Paulo: IBRASA, 1981. (Biblioteca, Psicologia e Educação, 78).

RODRIGUES, Charles; BLATTMANN, Úrsula. Gestão da informação e a importância do uso de fontes de informação para geração de conhecimento. Perspectivas em Ciência da Informação, v. 19, n. 3, p. 4-29, jul./set. 2014. Disponível em: http://www.scielo.br/pdf/pci/v19n3/a02v19n3.pdf. Acesso em: 15 fev. 2017.

SOUZA, S. C.; DOURADO, L.Aprendizagem baseada em problemas (APB): um método de aprendizagem inovador para o ensino educativo. Holos, v. 5, n. 31, 2015. Disponível em: http://www2.ifrn.edu.br/ojs/index.php/ HOLOS/article/view File/2880/1143. Acesso em: 12 jun. 2018. 
TOMAÉL, Maria Inês; VALENTIM, Marta Lígia Pomim (Orgs.). Avaliação de fontes de informação na Internet. Londrina: Eduel, 2004.

Recebido em: 06/02/2019

Aceito em: 20/06/2019

\section{EDITORA E GRÁFICA DA FURG}

CAMPUS CARREIROS

CEP 96203900

editora@furg.br 